\title{
Quadriceps muscle weakness influences the gait pattern in women with knee osteoarthritis
}

\author{
Deborah Hebling Spinoso ${ }^{1,5^{*}}$, Natane Ceccatto Bellei ${ }^{2}$, Nise Ribeiro Marques ${ }^{3}$ and Marcelo Tavella Navega ${ }^{4}$
}

\begin{abstract}
Background: Osteoarthritis is the most prevalent rheumatic disease in the population and is characterized by limitation of main functional activities of daily living, as the gait. Muscle strength is a variable that may be related to performance in daily tasks.Therefore, we to analyze the gait pattern in individuals with knee osteoarthritis (KOA) and to determine associations of gait variables with the level of muscle strength of knee extensors.

Methods: Sixty-seven female volunteers divided into 2 groups, a KOA group (KOAG, $n=36,66.69 \pm 7.69$ years) and control ( $n=31,63.68 \pm 6.97$ years), participated in the study. The volunteers walked on a 10-m platform at their usual gait speed, using 2 pressure sensors positioned at the base of the hallux and calcaneus. The mean step time, support and double support times, swing time and gait speed were calculated. The evaluation of the quadriceps isometric torque was performed in an extensor chair, with hip and knee flexion at $90^{\circ}$. The procedure consisted of three maximal contractions of knee extension. Peak torque was determined by the highest torque value obtained after the onset of muscle contraction. For statistical analysis, one-way ANOVA and Pearson's correlation were used, with $p<0.05$.
\end{abstract}

Results: The KOAG had a 54.76\% longer support time, a 13\% longer step time ( $p<0.001)$, a 30\% decrease in swing time $(p<0.001)$ and a $10.7 \%$ decrease in gait speed $(p=0.001)$ compared with controls. The quadriceps isometric torque was 34\% ( $p=0.001)$ lower in the KOAG. There was a correlation between kinematic variables and quadriceps torque.

Conclusion: Weakness of the quadriceps muscle in women with KOA influences gait pattern, resulting in reduced speed associated with a shorter swing time and longer support time.

Keywords: Kinematics, Torque, Falls

\section{Background}

Osteoarthritis (OA) is the most prevalent rheumatic disease in the population, characterized by progressive degeneration of cartilage and periarticular tissue, which results in changes in joint mechanics and may result in functional disability [1]. OA has a high incidence in the population; at least $30 \%$ of men and women over 65 years old have some radiographic alterations, and one-third of them are symptomatic [2]. In addition, in the age group

\footnotetext{
* Correspondence: deborahebling@yahoo.com.br

${ }^{1}$ Department of Physical Education, São Paulo State University, UNESP, Rio Claro, SP, Brazil

${ }^{5}$ Departamento de Fisioterapia e Terapia Ocupacional, Universidade Estadual Paulista, Avenida Hygino Muzzi Filho, 737, CEP, Marília, SP 17525-000, Brazil Full list of author information is available at the end of the article
}

of over 75 years old, the incidence increases to $85 \%$ because the older the population, the greater the number of individuals affected by the disease [3].

It is estimated that $4 \%$ of the Brazilian population has OA in at least one joint [4]. In $37 \%$ of these cases, the knee is the main affected region because in occupational and leisure activities, it is exposed to maximal compressive loads that can exceed three times that produced by the individual's body weight during walking. This stress favors high injury rates and cartilage degeneration, contributing to a greater incidence of OA in this joint [4].

Approximately $25 \%$ of individuals with knee osteoarthritis (KOA) cannot perform the main activities of daily living due to pain, muscle weakness, reduced balance,

(c) The Author(s). 2018 Open Access This article is distributed under the terms of the Creative Commons Attribution 4.0 International License (http://creativecommons.org/licenses/by/4.0/), which permits unrestricted use, distribution, and 
proprioception deficits, reduced joint range of motion and joint instability [5, 6]. Among the possible limitations caused by KOA, gait difficulty has great clinical relevance because it is the most performed daily life activity and ensures functional independence [7].

The gait is a complex task and requires a perfect harmony of the sensory, motor and cognitive systems to produce a stable, efficient and safe gait pattern [8]. Biomechanical gait pattern changes, such as reduction of gait speed, step length and width, increase of the double support phase time, shorter swing phase time and reduction of heel contact with the ground, among other parameters, can be observed through kinematic gait analysis [8]. These gait pattern changes are often reported in the elderly, and the causes are multifactorial, but the main factor related to gait performance is decreased muscular strength of the lower limbs [9].

In individuals with KOA, the reduction of the knee extensor strength has been noted as the main symptom of the disease because there is a reduction of approximately $50-60 \%$ of quadriceps maximum torque in relation to the young population, possibly resulting from atrophy by disuse, secondary to joint pain and arthrogenic muscle inhibition [10-12]. This loss of strength is more significant than that presented by the healthy population in the same age group that reaches 30 to $40 \%$ of maximum capacity [12]. The quadriceps weakness observed in this population can decrease the shock absorption capacity during walking, leading to accentuated symptoms and, consequently, gait pattern alteration as a strategy to minimize pain and maintain functionality $[9,13]$.

Previous studies have noted that the quadriceps is one of the main muscle groups responsible for increasing gait speed and has an important role in maintaining functional mobility. Weakness of this muscle group may be responsible for increased metabolic expenditure during functional activities, which limits the intensity and duration of these tasks $[14,15]$. Therefore, reduced ability to generate quadriceps strength, characteristic in patients with KOA, can negatively affect gait pattern, with a greater probability of becoming dependent on daily tasks, which leads to a decrease in quality of life and an increase in public expenditures to care services for this population $[12,13]$.

In this sense, gait analysis in patients with KOA can help identify changes in the gait pattern caused by the disease and, consequently, can help guide treatment and prevention programs for functionality loss in this population. The aim of the present study was to analyze the gait patterns of healthy individuals with KOA and to test for associations of gait variables with the strength level of the knee extensor muscles. We hypothesize that individuals with KOA will show decreased gait speed and swing time and longer step time in relation to controls and that these modifications are associated with lower knee extensor muscle strength in this population.

\section{Methods \\ Subjects}

Seventy-one female subjects, divided into a knee osteoarthritis group (KOAG) and a control group (CG), participated in this study. For the KOAG $(n=38,66.4 \pm$ 7.6 years), the individuals presented radiological diagnosis of tibiofemoral OA, confirmed according to the criteria of the American College of Rheumatology, and with grades II-III, based on the radiological grading scale of osteoarthritis described by Kellgren-Lawrence and WOMAC [16] pain scores greater than 21. For the CG ( $n=31,64.5 \pm 7.1$ years), the subjects had no history of changes related to chronic-degenerative diseases in the lower limbs. The sample size was determined by the G*Power program and was based on data obtained from pilot studies (effect $=0.85$, power $=0.95$, error $\alpha=0.05$, sample $N=15$ ).

The eligibility criteria for this study were as follows: age between 50 and 75 years, able to walk without gait devices and no other rheumatic diseases in the lower limbs, patellofemoral osteoarthritis, total or partial knee and/or hip arthroplasty, lesions in the lower limbs in the 6 months preceding the study or other diseases that made it impossible to perform the tests.

The present study was approved by the local ethics committee (n. 9032/2015), and obtained written informed consent from the patients for publication of data and images.

\section{Evaluation procedures}

The procedures for data collection were performed on 2 days, with an interval of two to 7 days between the collection days [17]. On the first day, anamnesis was performed to characterize the sample according to the anthropometric data and applying the WOMAC questionnaires to the KOAG. Subsequently, subjects were familiarized with isometric knee torque evaluation. On the second day, the isometric muscle strength of the knee and the gait were evaluated.

\section{Gait evaluation}

The gait evaluation was performed on a 14-m-long and 2 -m-wide catwalk, with the first $2 \mathrm{~m}$ and the last $2 \mathrm{~m}$ of the catwalk being disregarded for data analysis to avoid possible influences from the gait acceleration and deceleration process $[18,19]$.

After being familiarized with the gait test, the volunteers were instructed, through verbal stimulation, to walk on the catwalk at the speed they performed their 


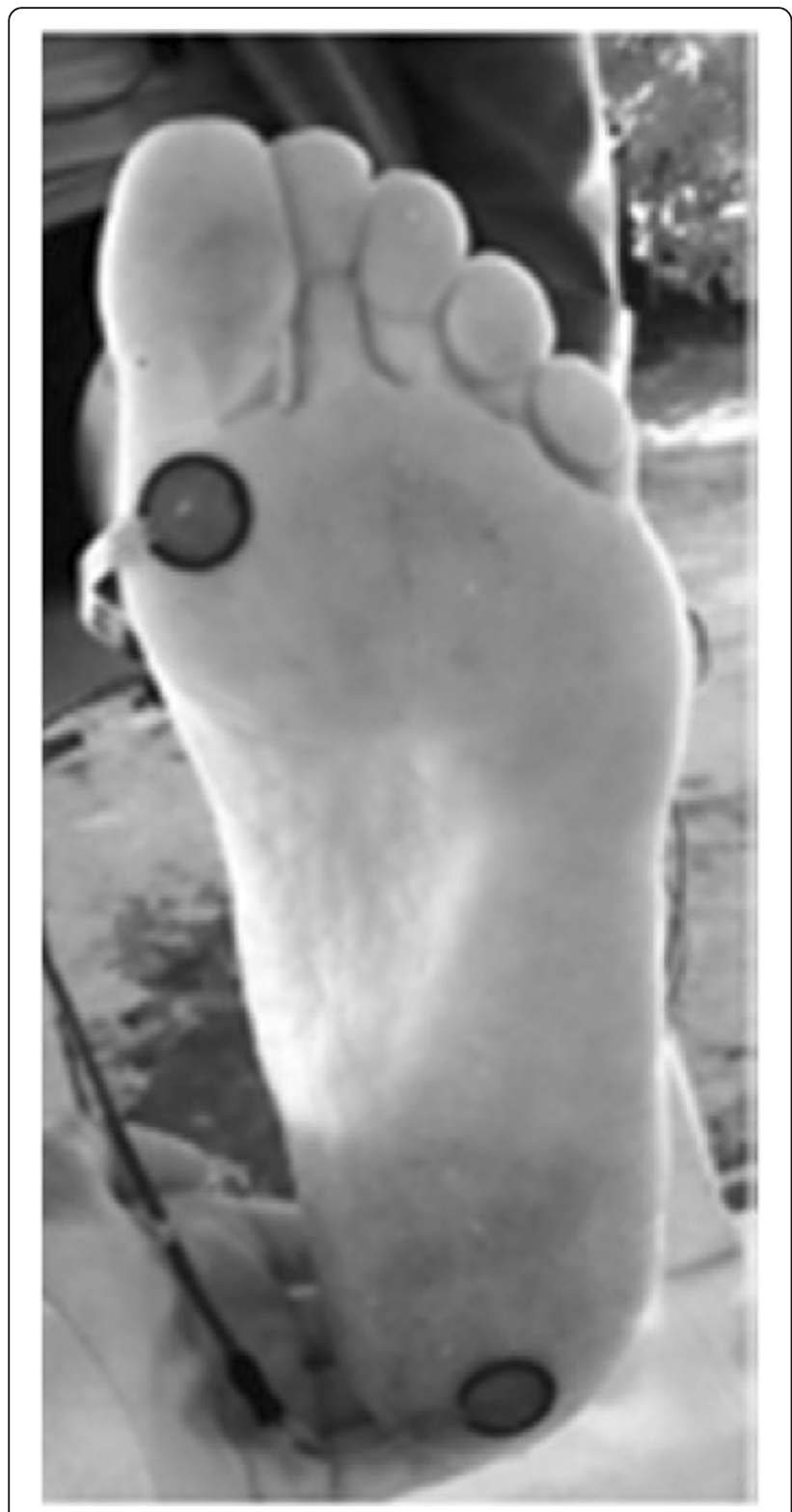

Fig. 1 Positioning of pressure sensors for gait analysis

daily activities [20, 21]. Five attempts to evaluate the gait were performed.

FootSwitch (Noraxon ${ }^{\oplus}$ ) pressure sensors positioned bilaterally on the calcaneus and at the hallux base were used to determine gait phases, as shown in Fig. 1.

\section{Evaluation of knee extensor torque}

The evaluation of knee extensor torque was performed on the affected lower limb for KOAG and on the dominant lower limb for the CG. Before the beginning of the evaluation protocol, a familiarization with the equipment, consisting of 2 submaximal contractions and 2 maximal contractions of the muscle group to be evaluated, was performed [22]. There was a 5-min interval between the familiarization and the beginning of the data collection procedures to avoid fatiguing the evaluated muscle group.

The evaluation protocol consisted of 3 maximal voluntary isometric contractions for the movement of the knee joint extension for a period of $5 \mathrm{~s}$, with a 30-s interval between each contraction [23]. The volunteers were seated in the chair extensor with hip and knee at $90^{\circ}$ flexion $\left(0^{\circ}\right.$ of full extension). The trunk and the contralateral lower limb were stabilized by belts. A loading cell $\left(\right.$ Noraxon $\left.^{\odot}\right)$ was coupled to the extensor chair lever for acquiring joint torque data. Figure 2 shows the positioning of the volunteer. The volunteers were instructed and encouraged to perform the movement as strongly and as quickly as possible.

The calculation of knee extensor torque was calculated from the following equation:

$$
\begin{aligned}
\text { Knee extensor torque }= & \text { Force }(N) \times \text { Distance } \\
& \times \operatorname{sen} 90^{\circ}
\end{aligned}
$$

\section{Data analysis}

Cardoso, B.C et al. [24] for gait data analysis, 40 steps and a 4th-order Butterworth filter with a cutoff frequency of $6 \mathrm{~Hz}$ were used. The mean step time (i.e., the

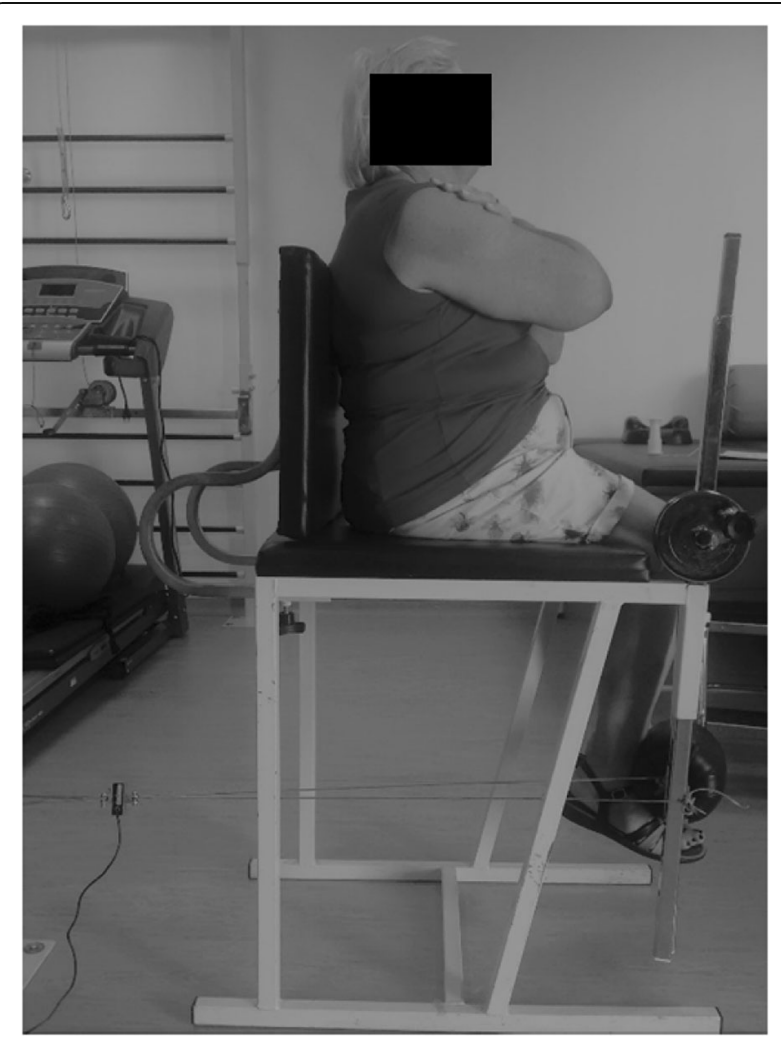

Fig. 2 Positioning of the volunteer for evaluation of muscle torque 
time between the touch of the right calcaneus until the same limb touched the ground again), support time (i.e., the time between the touch of the right calcaneus and the touch of the hallux of the same limb), swing time (i.e., the time between removal of the right hallux and the next touch of the calcaneus of the same limb), double support time and gait speed were calculated.

Muscle torque data were processed in routines developed in the Matlab environment (Mathworks ${ }^{\circ}$ ) using a 4th-order Butterworth filter with cutoff frequency of $15 \mathrm{~Hz}$ [25]. Torque data were normalized for the volunteers' body mass. Peak torque was determined from the highest torque value obtained after the onset of muscle contraction.

\section{Statistical analysis}

For statistical analysis, the program PASW statistics $18.0^{\circ}$ (SPSS) was used. After verifying the normality of the data, one-way ANOVA for comparisons between the groups and Pearson's correlation were applied, considering $p<0.05$.

\section{Results}

Table 1 presents the characteristics of the study participants. There were no differences between groups for anthropometric characteristics. Regarding the limb affected by the disease, 32 volunteers presented diagnosis in the dominant limb and 6 in the non-dominant limb.

The one-way ANOVA showed a significant difference between the groups, with the KOAG presenting a $54.76 \%(p<0.001)$ greater support time and a greater step time $(p<0.001)$. In addition, the swing time and the gait speed were $30 \%(p<0.001)$ and $10.7 \%(p=$ $0.001)$ lower, respectively, than those of the control volunteers. The double support time in the KOAG was 33\% greater than the CG $(p=0.02)$, as shown in Table 2 .

Regarding the muscle torque of knee extensors, the KOAG presented a $34 \%(p=0.001)$ reduction in peak torque compared with healthy individuals.

Table 1 Sample characterization

\begin{tabular}{|c|c|c|c|}
\hline & $\mathrm{KOAG}(n=38)$ & $C G(n=33)$ & $\mathrm{P}$ \\
\hline Age (years) & $66.49 \pm 7.64$ & $64.52 \pm 7.12$ & 0.36 \\
\hline Body weight (kg) & $76.51 \pm 14.77$ & $67.42 \pm 11.39$ & 0.22 \\
\hline Height (m) & $1.56 \pm 0.06$ & $1.55 \pm 0.05$ & 0.88 \\
\hline BMI $\left(\mathrm{kg} / \mathrm{m}^{2}\right)$ & $31.01 \pm 4.86$ & $27.94 \pm 4.58$ & 0.96 \\
\hline \multicolumn{4}{|l|}{ WOMAC questionnaire } \\
\hline Pain intensity (0-20) & $8.87 \pm 2.93$ & $0.33 \pm 0.56$ & $<0.001^{*}$ \\
\hline Stiffness (0-8) & $3.08 \pm 1.61$ & 0 & $<0.001^{*}$ \\
\hline Physical fitness (0-68) & $30.70 \pm 6.06$ & $5.70 \pm 2.33$ & $<0.001^{*}$ \\
\hline Total (0-96) & $42.66 \pm 8.61$ & $6.04 \pm 2.36$ & $<0.001^{*}$ \\
\hline
\end{tabular}

Table 2 Comparison of gait kinematic variables and quadriceps strength in subjects with $\mathrm{KOA}$ and healthy subjects

\begin{tabular}{llll}
\hline & KOA & Healthy subjects & $P$ \\
\hline Speed $(\mathrm{m} / \mathrm{s})$ & $1.00 \pm 0.13$ & $1.12 \pm 0.15$ & 0.001 \\
Support time (s) & $0.65 \pm 0.20$ & $0.42 \pm 0.10$ & $<0.001$ \\
Swing time (s) & $0.42 \pm 0.13$ & $0.60 \pm 0.13$ & $<0.001$ \\
Step time (s) & $1.13 \pm 0.12$ & $1.00 \pm 0.10$ & $<0.001$ \\
Knee extensor torque $(\mathrm{Nm} / \mathrm{kg})$ & $0.96 \pm 0.35$ & $1.44 \pm 0.42$ & 0.001 \\
\hline
\end{tabular}

Mean values \pm standard deviations, $m$ meters, s seconds, $\mathrm{Nm} / \mathrm{kg}$ Newton meters per kilogram

There were correlations between the knee extensor torque and the support time $(r=-0.552, p=0.03)$, step time $(r=-0.492, p=0.017)$ and gait speed $(r=0.442, p$ $=0.04)$, as shown in Table 3 .

\section{Discussion}

The results of this study corroborate the initial hypotheses that individuals with KOA show impairments in all gait kinematic parameters compared with healthy volunteers, and these biomechanical changes are correlated with knee extensor weakness.

Changes in the movement patterns during gait occur with advancing age and are well established in the literature. However, in individuals with $\mathrm{KOA}$, these changes are more pronounced and have a negative impact on the independence level in performing daily tasks [9]. Muscle pain and weakness are the main symptoms of the disease associated with changes in the spatial-temporal gait parameters that aim to minimize pain and protect the knee joint [9]. In the present study, women in the KOAG had a 34\% decrease in knee extensor strength compared with the control. According to Park et al. [12], the muscle strength deficit in KOA affects all lower limbs and is more pronounced in the knee extensors, being 40\% lower in relation to individuals of the same age group without KOA. Strength levels also showed a negative correlation with support/step time, indicating that muscle weakness results in gait temporal changes that lead to reduced gait speed. These findings corroborate studies by Resende et al. (2011) and Feber et al. (2016), who observed that gait pattern changes are associated with knee pain symptoms and weakness of the anterior thigh muscles $[10,11,26]$.

Table 3 Correlation between knee extensor torque and gait variables

\begin{tabular}{lllll}
\hline & Support time & Step time & Swing time & Gait speed \\
\hline Torque & & & & \\
$R^{2}$ & -0.552 & -0.492 & -0.318 & 0.442 \\
$P$ & 0.003 & 0.017 & 0.08 & 0.04 \\
\hline
\end{tabular}


According to Ploutz-Snyder et al. [27] and Manini et al. (2010), individuals with knee extensor torque values below $1.5 \mathrm{Nm} / \mathrm{kg}$ are classified as having mobility limitations and difficulty in performing daily tasks due to less capacity to generate force in the quadriceps $[27,28]$. In the present study, the volunteers with KOA showed extensor torque values that were $36 \%$ below the threshold proposed by those authors, and the CG presented values that were $4 \%$ below proposed values, which indicates greater functionality impairment of these individuals observed through the score obtained in the WOMAC questionnaire.

The muscles around the knee produce movement but also provide stability and control the load imposed on the joint; therefore, these muscles are related to the development and progression of KOA [12, 29, 30]. According to Kean et al. [31], maximal knee joint loads during gait occur because of muscle weakness, especially of knee extensors, which compromise the lower limb deceleration function before contact with the ground to reduce impact. Therefore, the strategy adopted by KOA patients is to reduce gait speed.

According to Kaufman et al. [32], patients with KOA tend to walk at slower speeds and with greater joint stiffness to avoid high external joint movements on the joint, i.e., the gait speed reduction is a strategy to decrease the vertical component of the soil reaction force imposed on the knee joint, reducing the functional demand in this joint. The lower usual gait speed observed in the KOAG can be considered a compensatory response to reduce joint stress during movement.

The literature establishes an ideal value for gait speed of $1.2-1.4 \mathrm{~m} / \mathrm{s}$ to perform daily tasks, including street crossing [33]. The women with KOA who participated in the present study had an average speed below the threshold value for what is considered safe, corroborating the findings of Tas et al. [34] and Gill et al. [35], which point to this speed reduction in KOA as a risk factor for future falls, functional decline and mortality in this population.

Modifications in the gait kinematic pattern may also justify the speed reduction observed in the KOAG. The decrease in the swing time observed in the KOAG (30\% lower) is in agreement with Bennell et al. (2013), who mentioned that the shorter swing time is due to weakness of the knee extensor muscles, which are not able to provide dynamic stability during the total weight placed over the limb at that gait phase. However, the increases in support time, step time and double support may be related to the possibility of generating a greater load distribution in the healthy limb. However, this compensatory response may contribute to joint wear and tear in the long term. According to Resende et al. (2011), if individuals with KOA stayed in the support phase longer, it is possible that the prolonged effect of a minor overload would be close to the short effect of an intense joint stress, i.e., the protective neuromuscular response may cause pain and joint damage. Thus, when the strategy of the movement changes due to pain or reduced capacity to stabilize a segment, joint overloads and early fatigue occur [13].

The limitations of this study are related to the approach involving only the knee extensor muscles, as this muscular group is the most affected by the disease. However, it is known that muscular weakness affects the entire lower limb, and studies by Bennell et al. (2010) and Amiri et al. [29] emphasize the importance of the hip abductor muscles and plantar flexors, respectively, in the gait pattern of individuals with KOA as a strategy to compensate for the deficit of quadriceps strength. Therefore, future studies should include other muscle groups of the lower limb to better understand the biomechanical gait changes in KOA.

\section{Conclusion}

There is a potential relationship between gait kinematic variables and knee extensor strength, and the weakness of the quadriceps muscle influences the gait pattern in individuals with KOA. This relationship results in the reduction of gait speed, associated with greater support/ step time and shorter swing time. Given that KOA has no cure and changes in gait are progressive and increase as the degenerative disease progresses, this study aims to contribute to directing physiotherapeutic interventions in KOA treatment by identifying the relationships between knee extensor strength and gait kinematic variables. Thus, physiotherapy can develop strategies focused on lower limb strength training, with a greater emphasis on the quadriceps muscle, which is more compromised in this population, and on activities that aim at gait training, seeking a better distribution of body weight in both limbs and improvements of range of motion and muscle recruitment, thereby improving the performance of the individual during daily tasks and contributing to slow down the progression of OA.

\footnotetext{
Acknowledgements

The authors appreciate the participation of all the volunteers of this research and financial support FAPESP.

\section{Funding}

The São Paulo Research Foundation (FAPESP) for financial support.

Availability of data and materials

Data from this manuscript will be available upon request.

Authors' contributions

Data Collection: D.H. Spinoso and N.C. Bellei. Data Analysis: D.H. Spinoso, N.C.Bellei, N.R. Marques. Manuscript Writing: D.H. Spinoso, N.R. Marques, and M.T. Navega. The authors further declare that this manuscript was approved for publication in the Brazilian Journal of Rheumatology.
} 


\section{Ethics approval and consent to participate}

This study were approved by the Ethics and Research Committee of the State University of São Paulo (1.503.496/2015) and all participants gave their written informed consent to participate and publication of the data.

\section{Consent for publication}

The authors agree with the publication of this manuscript in the jornal Advances in Rheumatology and were fully involved in the study and preparation of the manuscript (below we detailed the part played by each author).

\section{Competing interests}

The authors declare that none had any conflict of interest which could bias the results of this study and the material in this manuscript has not been and will not be submitted for publication elsewhere.

\section{Publisher's Note}

Springer Nature remains neutral with regard to jurisdictional claims in published maps and institutional affiliations.

\section{Author details}

'Department of Physical Education, São Paulo State University, UNESP, Rio Claro, SP, Brazil. ${ }^{2}$ Department of Physiotherapy and Occupational Therapy, São Paulo State University, UNESP, Marilia, SP, Brazil. ${ }^{3}$ Department of Health Sciences, University of the Sacred Heart, USC, Bauru, SP, Brazil. ${ }^{4}$ Lecturer in Musculoskeletal Physiotherapy Department of Physiotherapy and Occupational Therapy, São Paulo State University, UNESP, Marília, SP, Brazil. ${ }^{5}$ Departamento de Fisioterapia e Terapia Ocupacional, Universidade Estadual Paulista, Avenida Hygino Muzzi Filho, 737, CEP, Marília, SP 17525-000, Brazil.

Received: 3 July 2018 Accepted: 3 August 2018

Published online: 31 August 2018

\section{References}

1. Lim J, Tchai E, Jang SN. Effectiveness of aquatic exercise for obese patients with knee osteoarthritis: a randomized controlled trial. Am Acad Phys Med Rehabil. 2010;2(8):723-31.

2. Fernandes WC, Machado A, Borella C, Carpes F. Influência da velocidade da marcha sobre a pressão plantar em sujeitos com osteoartrite unilateral de joelho. Rev Bras Reumatol. 2014;54(6):441-5.

3. Neto EMF, Queluz TT, Freire BF. Atividade física e sua associação com qualidade de vida em pacientes com osteoartrite. Rev Bras Reumatol. 2011; 51(6):539-49.

4. Senna ER, De Barros AL, Silva EO, Costa IF, Pereira LV, Ciconelli RM, et al. Prevalence of rheumatic diseases in Brazil: a study using the COPCORD approach. J Rheumatol. 2004;31(3):594-7.

5. Jorge RT, Souza MC, Chiari A, Jones A, Fernandes AD, Junior IL, et al. Progressive resistance exercise in women with osteoarthritis of the knee: a randomized controlled trial. Clin Rheabil. 2014;29(3):234-43.

6. Edmonds DW, Mcconnell J, Ebert JR, Ackland TR, Donnelly CJ. Biomechanical, neuromuscular and knee pain effects following therapeutic knee taping among patients with knee osteoarthritis during walking gait. Clin Biomech. 2016;39:28-43.

7. Alkjaer T, Raffalt PC, Dalsgaard H, Simonsen EB, Petersen NC, Bliddal H, et al. Gait variability and motor control in people with knee osteoarthritis. Gait Posture. 2015;42:479-84.

8. Jahn K, Zwergal A, Schniepp R. Gait disturbances in old age. Deutsches Arteblatt International. 2010;107(17):306-16.

9. Clermont CA, Barden JM. Accelerometer-based determination of gait variability in older adults with knee osteoarthritis. Gait Posture. 2016;50:126-30.

10. Callahan DM, Tourville TW, Slauterbeck JR, Ades PA, Stevens-lapsley J, Beynnon BD, et al. Reduced rate of knee extensor torque development in older adults with knee osteoarthritis is associated with intrinsic muscle contractile deficits. Exp Gerontol. 2015;72:16-21.

11. Davison MJ, Maly MR, Keir PJ, Hapuhennedige SM, Kron AT, Adachi JD, et al. Lean muscle volume of the thigh has a stronger relationship with muscle power than muscle strength in women with knee osteoarthritis. Clin Biomech. 2017:41:92-7.

12. Park SK, Kobsar D, Ferber R. Relationship between lower limb muscle strength, self-reported pain and function, and frontal plane gait kinematics in knee osteoarthritis. Clin Biomech. 2016;38:68-74.
13. Kierkegaard S, Jorgensen PB, Dalgas U, Soballe K, Mechlenburg I. Pelvic movement strategies and leg extension power in patients with end-stage medial compartment knee osteoarthritis: a cross-sectional study. Arch Orthop Trauma Sur. 2015;135(9):1217-26.

14. Abreu SSE, Caldas CP. Velocidade de marcha, equilíbrio e idade: um estudo correlacional entre idosas praticantes e idosas não praticantes de um programa de exercícios terapêuticos. Rev Bras Fisioter. 2008;12(4):324-30.

15. Marques NR, LaRoche DP, Hallal CZ, Crozara LF, Morcelli MH, Karuka AH, Navega MT, Gonçalves M. Association between energy cost of walking, muscle activation, and biomechanical parameters in older female fallers and non-fallers. Clin Biomech. 2013;28(3):330-6.

16. Murray AM, Thomas AC, Armstrong CW, Pietrosimone BG, Tevald MA. The associations between quadriceps muscle strength, power, and knee joint mechanics in knee osteoarthritis: a cross-sectional study. Clin Biomech. 2015:30:1140-5.

17. LaRoche DP, Millett ED, Kralian RJ. Low strength is related to diminished ground reaction forces and walking performance in older women. Gait Posture. 2011;33(4):668-72

18. Doi T, Yamaguchi R, Asai T, Komatsu M, Makiura D, Shimamura M, Hirata S, Ando $\mathrm{H}$, Kurosaka $\mathrm{M}$. The effects of shoe fit on gait in community-dwelling older adults. Gait Posture. 2010;32(2):274-8.

19. Hollman JH, Kovask FM, Kubit JJ, Linbo RA. Age-related differences in spatiotemporal markers of gait stability during dual task walking. Gait Posture. 2007;26(1):113-7.

20. Bertucco M, Cesari P. Dimensional analysis and ground reaction forces for stair climbing: effects of age and task difficulty. Gait Posture. 2009;29(2):326-31.

21. Perry CJ, Kiriella JB, Hawkins KM, Shanahan CJ, Moore AE, Gage WH. The effects of anterior load carriage on lower limb gait parameters during obstacle clearance. Gait Posture. 2010;32(1):57-61.

22. Costa RA, Oliveira LM, Watanabe SH, Jones A, Natour J. Isokinetic assessment of the hip muscles in patients with osteoarthritis of the knee. Clinics. 2010;65(12):1253-9.

23. Hartmann A, Knols R, Murer K, Bruin ED. Reproducibility of an isokinetic strength-testing protocol of the knee and ankle in older adults. Gerontology. 2009;55(3):259-68.

24. Cardoso, B.C.; Pimentel, N.Li; Bellei, N.C; Nishiomoto, D.N.; Navega, M.T.; Spinoso, D.H. Efeito da bandagem elástica na ativação muscular do quadríceps e torque isométrico dos extensores de joelho em indivíduos com osteoartrite de joelho. Revista Brasileira de Educação Fiśsca e Esporte, jan/mar, 2017.

25. Crozara LF, Morcelli MH, Marques NR, Hallal CZ, Spinoso DH, Neto AA, et al. Motor readiness and joint torque production in lower limbs of older women fallers and non-fallers. J Electromyogr Kinesiol. 2013;23(5):1131-8.

26. Ferber R, Kobsar D, Park S. Relationship between lower limb muscle strength, self-reported pain and function, and frontal plane gait kinematics in knee osteoarthritis. Clin Biomech. 2016;38:68-74.

27. Ploutz-Snyder LL, Manini T, Ploutz-Snyder RJ, Wolf DA. Functionally relevant thresholds of quadriceps Femoris strength. J Gerontol. 2002;57(4):144-52.

28. Manini $T M$, Newman AB, Fielding R, Blair SN, Perri MG, Anton SD, et al. Effects of exercise on mobility in obese and nonobese older adults. Obesity (Silver Spring). 2011;18(6):1168-75.

29. Amiri P, Hubley-Kozey CL, Landry SC, Stanish WD, Astephen-Wilson JL. Obesity is associated with prolonged activity of the quadriceps and gastrocnemii during gait. J Electromyogr Kinesiol. 2015;25(6):951-8.

30. Hodges PW, Van Den HW, WRigley TV, Hinman RS, Bowles KA, Cicuttini F, et al. Increased duration of co-contraction of medial knee muscles is associated with greater progression of knee osteoarthritis. Man Ther. 2016;21:151-8.

31. Kean CO, Hinman RS, Wrigley TV, Lim BW, Bennell KL. Impact loading following quadriceps strength training in individuals with medial knee osteoarthritis and varus alignment. Clin Biomech. 2017:42:20-4.

32. Kaufman KR, Hughes C, Morrey BF, Morrey M, An K. Gait characteristics of patients with knee osteoarthritis. J Biomech. 2001;34(7):907-15.

33. Lui B, Hu X, Zhang Q, Fan Y, Li J, Zou R, Zhang M, et al. Usual walking speed and all-cause mortality risk in older people: A systematic review and meta-analysis. Gait Posture. 2016;44:172-7.

34. Tas S, Güneri S, Baki A, Yildirim T, Kaymak B, Erden Z. Effects of severity of osteoarthritis on the temporospatial gait parameters in patients with knee osteoarthritis. Acta Orthop Traumatol Turc. 2014;48(6):635-41.

35. Gill SV, Hicks GE, Zhang Y, Niu J, Apovian CM, White DK. The association of waist circumference with walking difficulty among adults with or at risk of knee osteoarthritis: the osteoarthritis initiative. Osteoarthritis Cartilage. 2017: 25(1):60-6. 